\title{
LA CONSTRUCCIÓN DE LOS SUJETOS DE LA EDUCACIÓN
}

María Verónica Di Caudo

Docente de la Universidad Politécnica Salesiana (Ecuador)

Los hombres no se hacen en el silencio, sino en la palabra, en el trabajo, en la acción, en la reflexión.

P. Freire

1. Educación: entre utopías y críticas, entre conflictos y diálogos

El título de este trabajo convoca a dos sujetos protagónicos implicados en lo educativo: el educando y el educador. Sujetos que vivieron, viven o vivirán en nosotros, que se moverán en nuestro imaginario y que por tanto, le dictarán a nuestra conciencia (o inconciencia) muchas de nuestras opciones, formas de pensar, acciones y sentires.

Intentamos en estas páginas contribuir a la reflexión sobre el devenir de estos sujetos de la educación y los papeles que juegan. Para esto, partimos de ciertas afirmaciones que destacan el valor y el sentido de la educación:

- Sin educación no hay posibilidad de llegar a ser persona en el sentido pleno de la palabra. Esto es: la meta de la educación es la humanización o personalización. "No es cuestión de ser mejor o peor, si- 
no de ser auténticamente hombre" (SAAVEDRA, 2006) $)^{1}$ Esta afirmación implica creer en la capacidad de la persona para educarse o perfeccionarse constantemente. Este privilegio acompaña al ser humano hasta el término de sus días (educación permanente).

- El proceso educativo no es uno de ajuste o de adaptación social. La educación permite tanto el desarrollo social como la maduración y el perfeccionamiento del ser humano, esto implica la capacidad y calidad de relaciones, un obrar libre y responsable en base a una correcta jerarquía de valores.

- El derecho de todos los hombres y mujeres a la educación (basamento de la dignidad de la persona) incluye el derecho a la educación de todo el ser humano. Principio que subraya el carácter verdaderamente integral: dimensión corporal, intelectual, afectiva, estética, social, volitiva, espiritual, formación científica, física, psicológica, moral. La persona es una unidad bio-psíquica-espiritual en interacción social y la formación integral consiste en humanizar y personalizar al ser humano, este es el objetivo mayor que persigue toda la educación genuina.

- Todo proceso educativo requiere de un encuentro personal, de diálogo, de un ida y vuelta de comunicación y encuentro (aunque este sea virtual o a distancia), con el contexto y con otros seres humanos.

- En todo acto educativo subyace una direccionalidad, una intencionalidad (dimensión teleológicoaxiológica). Se ayuda a educar a través del desarrollo intencionado. Por lo tanto, conocer cuáles son tanto las razones últimas (fines) como las inmediatas (objetivos) y los valores que postula cualquier propuesta pedagógica constituyen un deber pri- 
mordial para saber que sujetos se están construyendo (o se pretenden construir) o los que quieren "eliminarse".

Estas son enunciaciones "clásicas", conocidas seguramente para el lector de estas páginas. Pueden resultar pasadas de moda en un momento en que se habla de "crisis educativa”, en donde la pedagogía aparece cuestionada desde su autoridad y desde la productividad de otros espacios culturales, donde los saberes que imparte la escuela resultan amenazados, donde la función del maestro está en continuo deterioro.

Las anteriores, pueden ser afirmaciones poco creíbles porque numerosas teorías críticas han expuesto la imposibilidad de la pedagogía moderna -emancipadora o revolucionaria- según la cual las ciencias humanas y las ciencias de la educación entre ellas, tienen el cometido de liberar al hombre y la humanidad (JÓDAR Y GÓMEZ, 2005). ${ }^{2}$ En este contexto, Lerena ha planteado que la educación esconde en el precepto humanista una operación política productora de sujetos:

"Con el término educación no estamos ante un concepto, sino ante un precepto: el precepto humanista con el que las clases dominantes del siglo de las luces han inaugurado la legitimación de una estrategia política. Uno de los efectos globales de esta estrategia es el de producir la singularidad y la individualidad del hombre contemporáneo. Realmente lo que designa la palabra educación es una determinada jurisdicción de poder, tal y como este se estructura en el siglo de las luces. Dentro de esa jurisdicción los individuos devienen y se constituyen en sujetos en la medida en que el poder hace de ellos su objeto" (Lerena, 1983: 9). ${ }^{3}$

El proyecto de liberación del hombre ignora que las ciencias humanas llevan consigo el poder de formación 
de los sujetos para que estos puedan adaptarse a las configuraciones vigentes del poder. Como instituciones eminentemente políticas, las instituciones educativas están profundamente involucradas en la reproducción de los valores sociales, económicos y culturales vigentes, así como en la conservación de esas formas sociales dominantes que reproducen las configuraciones actuales de poder.

Desde esta perspectiva de análisis, podemos sentarnos a llorar sintiéndonos presos de las estructuras de poder o plantearnos una ubicación distinta considerando que las instituciones son también lugares de mediación, oposición y nuevas posibilidades y "no son simples tamices fijos dentro del aparato reproductor del sistema" (Giroux). ${ }^{4}$ En cuanto, instituciones críticas surgen espacios abiertos a nuevas posibilidades que tienen muy en cuenta la producción de saber, identidades sociales y valores. Estos espacios deben ser potencializados por sujetos que escapen a ciertas lógicas mecánicas de reproducción.

Giroux habla de "pedagogía del riesgo" que es la que se convierte en una actividad cívica que busca ampliar las condiciones de justicia y democracia, las capacidades críticas de las personas, y eliminar la violencia material y simbólica de la sociedad, en vez de cerrarlas. La pedagogía del riesgo es la opuesta a una sin autocrítica, e implica que los sujetos educativos aprendan a tomar postura, debatir y esforzarse colectivamente para convertirse en sujetos de la historia. Esta visión realza a la pedagogía como discurso de transformación y proyecto de posibilidades. ¿Qué riesgos corren los estudiantes y qué riesgos les dejamos correr (sin miedo a la censura, a la evaluación y al castigo)? ¿Qué riesgos estamos dispuestos a correr como educadores? ¿Qué riesgos podemos correr dentro de nuestras instituciones para dialogar como sujetos autónomos con el poder y el orden "preestablecido"? 
La pedagogía debe considerarse siempre como un lugar de conflicto y diálogo. Giroux dice que debemos preguntarnos: ¿de quién son los valores, identidades, conocimientos y relaciones sociales que se están produciendo? En otras palabras, ¿quién habla, para quién y en qué condiciones? Hay que buscar y contextualizar los referentes éticos y políticos que le dan sentido en la historia, la lucha y la intervención humanas.

Sabemos entonces que no existe "lo natural", ni lo objetivo, ni lo ahistórico, ni lo neutro. Y que no podemos reflexionar sobre sujetos educables o educadores desligados de complejas interrelaciones con la política, el poder y la moralidad.

Tendremos que plantearnos: ¿Cómo habría que organizar el currículo y la vida educativa, cómo establecer las relaciones entre educadores y estudiantes para que ambos aprendan a pensar de forma crítica y autocrítica y a emitir juicios sobre la constitución y organización de la educación, de la sociedad, de nuestros propios discursos y subjetividades?

Según las respuestas que nos animemos a dar a estas y otras cuestiones, estaremos sí, reproduciendo sujetos o buscando generar intersticios de contrapoder que den lugar a sujetos con autonomía, que puedan moverse de los imaginarios sociales para crear "imaginarios radicales" 5 que, como constructos de sentido se constituyan en formas creativas de vivenciar el futuro, al articular la imaginación a los diferentes ámbitos de la vida social.

"En el imaginario se construyen nuevas maneras de vivir y el sujeto se construye a sí mismo, es capaz de soñar, de desear y de apostarle a utopías posibles. Es el sujeto con imaginario radical, un sujeto experiencial cuyos itinerarios fractales son construidos en relación y con intencionalidad, relación dada en dos planos: con los otros 
y en situación. La fractalidad de sus itinerarios de vida equivale "a señalar que, al caminar, vamos transformando ya el futuro más inmediato en pasado, simultáneamente vamos transformando ya el espacio vacío, desconocido y homogéneo, en espacio poblado, conocido y heterogéneo".

(HURTADO, 2004). ${ }^{6}$

En ese sentido, aún podemos crear en los espacios que otros discursos y prácticas preexistentes no alcanzaron, en esos espacios de libertad, que el simbolismo no alcanzó a determinar. Podemos recuperar la conciencia, la memoria, la voz y colocarnos como sujetos en el centro del debate.

\section{La educación es posible: educabilidad y educatividad}

La educabilidad es una posibilidad y una categoría humana, fundamento de la acción educadora. Significa la viabilidad del proceso educativo y la afirmación de que la educación es factible en la persona, básicamente por la condición de su plasticidad y ductilidad, que le permite recibir influencias y estímulos y reaccionar ante ellos, con lo cual elabora nuevas estructuras que lo personalizan y socializan, o, la capacidad que la persona tiene de adquirir nuevas conductas, de perfeccionarse y transformarse -a lo largo de su existencia- sea sistemáticamente por medio del educador y de instituciones pedagógicas, sea espontáneamente, por influencia del medio sociocultural. Esta potencialidad encierra un enorme potencial; el ser vivo es tanto más "plástico" o "dúctil", cuanto más compleja es su estructura biológica, y en el ser humano, las posibilidades son sorprendentes y la neurociencia no deja de hacer nuevos descubrimientos al respecto. 
Aunque la capacidad de "hacerse" o aprender no es ilimitada, el ser humano es educable a lo largo de su existencia, por lo que es un ser permanentemente inacabado y siempre en desarrollo, con nuevas capacidades de aprender. Así, la educabilidad no se contempla actualmente en términos ambientalistas, ni como una capacidad estática y conclusa, sino en función de la cantidad y calidad de los aprendizajes que va realizando; de ahí, el que la educabilidad no se agote en un período más o menos amplio del ciclo vital como se pensaba tradicionalmente, sino que la persona es capaz de aprender a lo largo de toda su existencia.

La propiedad del educador o educatividad es la posibilidad real de influir decisivamente en la formación de otra persona; es la acción propia e inherente de la función de todo educador. Esta capacidad puede aplicarse a instituciones como familia, escuela, comunidad local, etc.

La autoeducación en sentido absoluto no es posible pues el ser humano está sometido a influencias. Sin embargo, el aprendizaje es inmanente, por lo que la tarea de enseñar resultaría inútil si aquél no tiene lugar. La autoeducación en cuanto que supone la significación para el sujeto que aprende sí es posible. Se complementa con la heteroeducación en cuanto que, la actividad del educador facilita o ayuda al esfuerzo discente para conseguir un desarrollo de sus capacidades de un modo óptimo.

Por esto, la educación no es un simple accidente o detalle en nuestra existencia, es un hecho concreto que afecta y construye nuestra integralidad, de manera que sin ella la existencia humana perdería su sentido. Sin la educación el ser humano no adquiriría el lenguaje, los hábitos, las ideas y sentimientos que pertenecen a la vida cultural. Al decir de Kant: "únicamente por la educación el hombre llega a ser hombre”. 
Constantemente nos modificamos o transformamos, asimilamos conocimientos, corregimos defectos, adquirimos hábitos y modos de obrar; en suma, nos construimos. Todos somos influidos en nuestro modo de actuar, pensar, decidir por los efectos de la educación. Y todos ejercemos un estímulo educador sobre otras personas que nos rodean. En sentido general todos somos educadores y educandos a la vez.

Pero sabemos que la educación no es sólo función necesaria para el individuo sino para la sociedad, de manera ineludible. De esta forma, en la educación y, a través de ella, los sujetos pueden desarrollar sus potencialidades, transformarse y perfeccionarse y a su vez, incorporar las riquezas y elementos del contexto históricosocio-cultural.

"La educación es simultáneamente un proceso autónomo y heterónomo. Autónomo si consideramos la actividad creadora y libre del sujeto, la espontaneidad activa del educando como ser individual. Pero también es un proceso heterónomo si consideramos que este ser que se educa está sometido a influencias exteriores, a coacciones del medio natural y humano, a la presión de los valores y bienes culturales que han de modificar su desenvolvimiento espontáneo y natural". (MANGANIELLO: 18)7

\section{Sujeto educando: una contrucción entre la cultura y su propio desarrollo}

El educando (infante, joven, adulto) es un individuo, forma un número con los demás y se distingue por diversos caracteres individuantes (peso, sexo, edad, raza, etc.); pero al decir que además y por sobre todo es "persona" se afirma que cada uno como sujeto, realiza la especie "hombre" de un modo irrepetible e irremplazable. Esto 
implica que el educando, es mucho más que un apellido, un número de matrícula, una nota. Es igual a sí mismo y nada más. Esta manera rigurosamente singular de ser persona es la "unicidad".

La "unicidad" está fundamentada por la interioridad, o sea la capacidad del ser humano de pensar y obrar conscientemente y de decidir en forma autónoma y libre. Estas características son propias de todo ser humano aunque no siempre aparezcan explícitamente en el accionar pedagógico. Y por eso nos parece importante declararlas aquí, porque son el fundamento de toda construcción posterior (cf. Gastaldi, 2003). 8

Pero vayamos un paso más. El sujeto no puede construirse sólo desde su interioridad y unicidad. Necesita de los demás para crecer; la dimensión social es esencial y constitutiva del ser humano. Parafraseando a Ortega y Gasset, ${ }^{9}$ podríamos decir que cada "educando es él y sus circunstancias". El educando no puede prescindir de su contexto y está referido constantemente a él.

El educando no es un espectador pasivo en el mundo, sino que está en diálogo con él, con el mundo físico y el simbólico. Y en este espacio histórico-cultural, junto con otros sujetos, va a intentar realizar su propia existencia, creando ojalá, un mundo más humano.

César Coll explica muy claramente que:

"No habrá probablemente discrepancia alguna entre los profesionales de la educación si afirmamos que la finalidad última de ésta es promover el crecimiento de los seres humanos (...) Todos los procesos psicológicos que configuran el crecimiento de una persona -tanto los habitualmente considerados evolutivos, como los atribuidos también usualmente a aprendizajes específicos- son el fruto de la interacción constante que mantiene con un medio ambiente culturalmente organizado". 10 
Esta interacción del ser humano con su medio está mediatizada por la cultura, ${ }^{11}$ siendo los padres, los maestros, y demás adultos y grupos sociales, los principales agentes mediadores.

Jorge Huergo ${ }^{12}$ nos indica que: para pensar el campo cultural como educativo debemos comprenderlo como dialógico ${ }^{13}$ y, a la vez, conflictivo; como campo de articulación entre diferentes y sucesivas interpelaciones y los reconocimientos subjetivos que ellas provocan. ${ }^{14}$ Para esto, necesitamos trabajar con una noción de lo educativo que nos permita interpretar los territorios culturales revueltos, en cuanto, formadores de sujetos. Es posible sostener que "lo educativo» consiste en que, a partir de una práctica de interpelación, un agente se constituye en sujeto de educación activo incorporando de dicha interpelación algún nuevo contenido valorativo, conductual, conceptual, etc., que modifique su práctica cotidiana en términos de una transformación o en términos de una reafirmación más fundamentada (BUENFIL BURGOS, 1993).15 A partir de los modelos de identificación propuestos desde algún discurso específico (sea escolar, mediático u otro), el sujeto se reconoce en dicho modelo, se siente aludido o acepta ser lo que se le propone ser.

Esta noción es importante porque no es una vinculación pasiva con la cultura la que se transforma en educativa, sino que se necesita de una interpelación que modifique a la persona o que la reafirme. A su vez, y como la define Ávila Penagos, la cultura es "una inmensa red de significaciones", "un inmenso texto, abierto a las posibilidades de nuevas resignificaciones e interpretaciones a partir del trabajo reflexivo y critico que hace la práctica educativa con las nuevas generaciones" (PENAGOS, 2001).16 
Cada vez que las personas establecemos relaciones interpersonales con algún mediador, vamos desarrollando los procesos psicológicos superiores (PPS), competencias cognitivas que según estudios de Vigotsky aparecen siempre en primer lugar en el plano de la relación interpersonal -y en consecuencia sufren la mediación de los patrones culturales dominantes- para luego manifestarse en un plano intrapersonal.

Ahora, en esta relación entre la persona y la cultura, es necesario destacar que la cultura (que es una estructura supraindividual) no se impone, se estimula, se despierta y necesita de un ser humano autónomo y libre, que pueda actuar desde la cultura, en la cultura, para la cultura.

Desde la concepción psicosocial de Martín-Baró ${ }^{17}$ se destaca la importancia de la acción con significado. Él explica que lo que caracteriza fundamentalmente al sujeto humano, en cuanto ser vivo, es la acción, y no la conducta. Acción significa (en sentido weberiano), conducta dotada de significación o sentido. La misma génesis del significado de la acción humana es un fenómeno social, imposible sin la existencia de una comunidad de sentido, es decir, un conjunto de personas que compartan un código común. Por ello, la noción de acción rectifica a la de conducta en dos sentidos importantes, destacando por un lado el carácter propositivo de la actividad humana, intencional y motivada, y ligándola al mismo tiempo a estructuras sociales de significado.

De esta forma, el crecimiento personal es el proceso mediante el cual interiorizamos y nos apropiamos activamente de la cultura del grupo social al que pertenecemos. Y la educación, como realidad permanente en la vida individual y social, permite comprender cómo se articulan en un todo unitario la cultura y el desa- 
rrollo individual. Como sujetos insertos en una "comunidad de sentido" (educativa) nos construimos mutuamente en la acción, en la "común unidad" (cf. Estela Quintar).18

\section{Sujeto educador: una permanente construcción ética, política y comunitaria}

Generalmente, cada vez que se habla de mejorar la calidad educativa, los proyectos incluyen reformas en el rol docente, sea de formación, capacitación y desarrollo profesional.

"La enseñanza es una actividad que requiere compromiso, pasión, intención de generar y promover el cambio en la modalidad de pensamiento y en la visión que de la vida y del mundo social y natural tienen quienes están en situación de aprender (...) La innovación es tarea de transgresores. De aquellos que están convencidos de que el orden habitual y rutinario de la enseñanza debe ser alterado por nuevas formas de comunicación didáctica, por nuevas formas de entender y ejercer la enseñanza”. (LIBEDINSKY, 2001: 34, 38). ${ }^{19}$

Desde esta concepción, con la que estamos plenamente de acuerdo, los nuevos docentes serán los que busquen nuevos caminos, se arriesguen a cambios cualitativos, promuevan en sí mismos y en los demás actitudes de investigación, de autocontrol de intercambio de ideas, de experiencias y proyectos, de materiales, de participación colectiva, de creatividad. Docentes comprometidos con la tarea, confiados en sí mismos, motivados intrínsecamente, con iniciativas propias e independencia (más allá de toda condición laboral negativa). 
El papel de los maestros no puede detenerse. Desde siempre el maestro ha sido para el imaginario de muchos una figura de autoridad, transmisora de un saber infinito, cumpliendo un "apostolado" educativo. Con la explosión de los conocimientos y la rapidez de las comunicaciones, el maestro está llamado hoy a ser un mediador entre los sujetos y la información. Ya no es importante la memorización de la información; sino su selección, la utilización del conocimiento de manera crítica y creativa.

La revisión del rol docente y la definición más clara de lo que se espera de él, permite precisar que sus competencias profesionales no se agotan en la instrucción, en el trasvasamiento de contenidos; sino que alcanza al asesoramiento, a la orientación; el maestro compromete su ética a través de actitudes; con lo cual adquiere el verdadero papel de formador, de facilitador del aprendizaje. (ROGERS, C., 1986) ${ }^{20}$

Múltiples y actuales discursos pedagógicos afirman que el docente debe ser un ser comprometido, crítico, transformador, etc. Paulo Freire es un fuerte referente en pedagogía latinoamericana que puede iluminar este desafío. La formación docente inicial remite a las posibilidades y efectos que realmente genera en los sujetos. Por su parte, la concienciación es destacada por Freire como el camino para "poder salir de la alienación" para ser capaz de vivir la educación como práctica de la libertad. Esto requiere desde el docente-formador (el formador de formadores), un reconocimiento individual y social como sujeto-partícipe activo en los procesos sociales, que le permita interpretar la realidad para intervenir.

Michel Apple refiriéndose al concepto de concienciación de Freire, y compartiéndolo, explica que "darse cuenta" del mundo no significa, de ninguna manera, tomar la decisión de intervenir para transformarlo. En formación 
docente, es preciso tomar decisiones y "hacerse cargo" de iniciar el proceso de ruptura, que la vida y la experiencia profesional pueden o no abonar para que el "darse cuenta" se convierta en educación para la libertad (APPLE, 1996).21

La formación y capacitación docente debiera desarmar la "visión objetiva" de la realidad y del conocimiento de esa realidad, para generar docentes involucrados con el contexto y concientes del mismo y de las posibilidades de sus prácticas, en una relación dialógica o una unidad dialéctica constante entre el desarrollo de la práctica con el contexto teórico. Y darse cuenta que no existen acciones pedagógicas (ni ninguna otra) que sean neutras. Prácticas domesticadoras y reproductoras conducen sólo a la alineación y cierran las puertas a una praxis verdadera y a la construcción de sujetos.

"Mientras éste -el docente domesticador- es siempre el educador de los educandos, el educador para la liberación tiene que 'morir' como educador exclusivo de los educandos a fin de renacer, en el proceso, como educadoreducando de los educandos. Tiene que proponer, además, que los educandos mueran exclusivamente como 'educandos' del educador a fin de que renazcan como educandoseducadores del educando-educador" (Freire, 1969) ${ }^{22}$

Pensar en una formación para la emancipación, nos lleva a imaginar procesos colectivos de reconstrucción de la cultura.

“...No hay concientización fuera de la praxis, fuera de la unidad teoría-práctica, reflexión-acción”. (Freire, 1969), fuera de los movimientos sociales que articulan identidades llevándolas a participar de una construcción social colectiva de sentidos" (UMPIERRERZ) ${ }^{23}$

Espacios comunes de trabajo, investigación, debate y acción son espacios que hay que defender para 
construirnos como sujetos pedagógicos que no descuiden la función social y política que la docencia representa.

Si no logramos comprender esto, nos convertiremos en ejecutores de la "pedagogía bancaria" 24 que supone sujetos pacientes, receptivos, oyentes, sujetos que se constituyen en "objetos recipientes" 25 . Trascender esta conceptualización bancaria de la práctica educativa es condición impostergable a cualquier propuesta pedagógica que se pronuncie por una educación transformadora y liberadora y no meramente reproductora de las relaciones sociales de dominación vigentes. Este nuevo rol ayudará a que los educandos no sean consumidores de cultura e información, sino creadores y productores de valores y conocimientos.

Linda Darling Hammond (2001) ${ }^{26}$ explica que los docentes aprenden a medida que sus educandos aprenden: estudiando, haciendo y reflexionando; colaborando con otros docentes, observando cuidadosamente a los estudiantes y sus trabajos, y compartiendo lo que ven. Este tipo de aprendizaje no puede ocurrir en aulas de formación o capacitación docente divorciados del conocimiento acerca de cómo se interpreta la práctica. Los buenos entornos para el aprendizaje de docentes proveen muchísimas oportunidades para la investigación y la indagación, para ensayar y probar, para conversar sobre y evaluar los resultados del aprendizaje y de la enseñanza.

Todos los docentes necesitan tomar conciencia de su nuevo rol y trabajar grupal y comunitariamente, y no solos. El cuerpo docente deberá conocer, comprender y analizar las condiciones de sus educandos, las necesidades educacionales de la comunidad en la que trabaja, organizar experiencias de aprendizaje y evaluar constante y adecuadamente. Por estos caminos podrá revalorizar su responsabilidad social, como mediador entre la institu- 
ción educativa y la colectividad, entre la masa de información y el educando.

"Pareciera que más que especialistas en un determinado campo del saber, los nuevos tiempos requieren docentes capaces de integrar el conocimiento, de tomar una posición problematizadora frente a los múltiples saberes que circulan en la sociedad, de preguntarse colectivamente sobre la naturaleza del saber, sus modos de transmisión y utilización". (SANTOS GUERRA, 1993)27

Alejandra Birgin y Silvia Duschatsky (1995) ${ }^{28}$ en "Problemas y perspectivas de la formación docente", agregan: "Pero sobre todo, docentes inmersos y comprometidos con su contexto. La práctica docente se desarrolla en escenarios únicos, albergados en culturas y contextos particulares que no se derivan de la aplicación mecánica o instrumental de ciertas reglas o principios rígidos" (p. 112).

Toda formación y capacitación docente debiera apuntar a un compromiso serio con una labor humana, creativa y abierta que considere de manera integral al estudiante como un ser bio-psico-socio-cultural, en proceso de desarrollo y consolidación de su identidad, de su propia imagen y de su seguridad personal.

La calidad educativa no puede desligarse de la formación docente y esta última, no puede desarticularse de las condiciones sobre las que se construye toda la acción educativa de aspectos institucionales, organizativos, didácticos, curriculares, culturales, presupuestarios, políticos. (Castro, 1991)29

"La educación de los docentes debe estimular la capacidad para cuestionar las propias teorías, confrontar supuestos, conectarse con el conocimiento desde otro lugar y desarrollar la autonomía de pensamiento y de acción" (DAVINI, 1995: 127). ${ }^{30}$ 
Los profesores no encontrarán situaciones iguales, ni estudiantes, ni clases iguales. Por eso, es importante formarlos en estrategias que produzcan competencias profesionales "situacionales", dotándolos de capacidad de análisis, reflexión y de decisión ante situaciones complejas, inmediatas, simultáneas, etc. Esta formación requiere de una dialéctica entre teorización y práctica, de una amplia flexibilidad para aplicar esquemas prácticos a la realidad, de la conexión y el diálogo entre la formación teórica con las propias creencias sobre los hechos pedagógicos y la práctica.

Liston y Zeichner (1996) $)^{31}$ en "Formación del profesorado y condiciones sociales de la escolarización" presentan como un elemento importante las formas cooperativas de aprendizaje. Señalan que el refuerzo de los profesores individuales, en cuanto a individuos, es inadecuado y que el potencial para el cambio institucional y social es grande si los futuros profesores se dan cuenta de que sus situaciones individuales están ligadas a las de sus colegas, y si desarrollan las capacidades necesarias para trabajar con estos compañeros y con otras personas, como los padres y los activistas de la comunidad, para efectuar los cambios necesarios tanto en el aula como en las escuelas y en la sociedad.

Estos autores, desde una postura de orientación reconstruccionista social, enmarcan a la enseñanza en una concepción fundamentalmente política y destacan la importancia de trabajar con los "hechos" del contexto de trabajo de los alumnos, problematizarlos y someter a reflexión prácticas que ponen de manifiesto las diferencias raciales y de clase social. Subrayan que la formación docente debe orientarse a permitir discernir buenas razones que avalen las acciones educativas. 
Esta tradición reconstruccionista social ${ }^{32}$ (muy marginal por cierto, respecto a otros programas de formación de profesores) está segura que aunque la formación del profesorado no puede por si sola crear una sociedad mejor, puede cooperar en la lucha para hacerla realidad.

Sabemos que una pedagogía enseña no sólo por lo que dice que enseña, sino por el modo cómo lo enseña. La forma y la metodología, también es contenido. Giroux (1987), desde la sociología crítica nos explica que en muchos sentidos, los programas de formación del profesorado no han dotado a los profesores de las herramientas conceptuales que necesitan para concebir el conocimiento como algo problemático, como un fenómeno condicionado y creado históricamente. Esto lleva a pensar que el conocimiento no es neutro, sino que implica formas específicas de relaciones sociales en el aula, en las instituciones, en la sociedad. Cuando el conocimiento es visto como objetivo, Freire en "Pedagogía del Oprimido" nos enseña que no hay lugar para el diálogo y la interacción; pero si los estudiantes pueden crear significados, podrán pronunciarse con autenticidad y formarse como "intelectuales críticos" que puedan abordar la tarea de una toma de conciencia más radical e imaginativa entre colegas y alumnos.

"La futura reforma de la formación del profesorado tiene que comenzar por proporcionar a los estudiantes las herramientas teóricas y conceptuales para combatir toda clase de engaño y alienación. Los estudiantes deberían ser capaces, tanto de forma estructural como intelectual, de ahondar en las realidades de sentido común, en lo superficial, con el fin de configurar sus experiencias cotidianas. Asimismo debería dárseles a los alumnos la oportunidad de crear sus propios significados, hablar según les dicte su 
propia conciencia y llegar a comprender que siempre hay algo más que ver, oír y sentir" (GIROUX, 1987: 71).33

La innovación y la mejora de la calidad educativa no son un simple problema de capacitación o de nuevas metodologías, sino un problema mucho más amplio y complejo que afecta las condiciones de trabajo docente, en las cuales se implican las estructuras de la institución, la política curricular y la práctica curricular, etc. Al respecto, es imprescindible como indica Popkewitz (1996) reflexionar sobre los contextos institucionales y sociales donde se inserta la práctica docente. La reflexión crítica, es decir, la comprensión del trasfondo constitutivo de las prácticas, permitirá cuestionar la aparente neutralidad de las cosas y evitará así, su naturalización.

David Perkins (1999), en "La Escuela Inteligente" escribe que espera docentes que encuentren el optimismo y la orientación para luchar contra la frustración y el cansancio, producto de las presiones que se ejercen en la mayoría de los ámbitos escolares y hallen la confirmación de su buena práctica docente y también nuevas maneras de pensar acerca de la enseñanza y del aprendizaje. Que encuentren razones válidas para innovar, frente a la apatía y la desconfianza de las comunidades.

En síntesis, la formación docente -de grado o en servicio- requiere del desarrollo de estrategias grupales, de la priorización de procesos vinculares y comunicativos, de fomentar espacios comunes de aprendizaje y construcción del conocimiento compartido, de permanente reflexión y acción, de ir y venir de la teoría a la práctica y viceversa, de pensar dialécticamente, de ponerse de cara al contexto y la realidad, con sensibilidad histórica y mirada prospectiva. De optar, en definitiva, por una profesión política y ética en miras al progreso de cada estudiante y de la sociedad en su conjunto. 


\section{Descubrir al otro como sujeto y construirnos mutuamente}

Ante distintas disciplinas y discursos -que en el marco de la posmodernidad- postulan la defragmentación y/o ausencia del sujeto como uno de los problemas epistémicos más importantes, intentaremos presentar algunas ideas (filosóficas, pedagógicas, sociológicas) que pueden resultar estimuladoras para descubrir (o re-descubrir) al sujeto.

Hugo Zemelman ${ }^{34}$ aporta con su pensamiento desde América Latina y explica que estamos plagados de discursos, muchos de los cuales no tienen sujeto y, existen además, muchos sujetos en el continente que no tienen discurso. Y propone recuperar al sujeto como un sujeto erguido, es decir, un sujeto constructor, que se entiende a sí mismo en el ámbito de una realidad dada como ante una realidad construible, que se puede potenciar desde el presente y que se debe y puede potenciar no solamente desde el gran conocimiento acumulado. El conocimiento sin duda tiene presencia, pero no basta si no tiene también presencia el uso crítico del mismo y su uso como instrumento de transformación y autonomización de los sujetos (y no como simple erudición o información). Desde este ángulo tendría cabida la idea de transformar la conciencia histórica en una gran premisa desde la cual pensar y construir conocimiento.

Hargreaves (2000), ${ }^{35}$ hace una crítica a la estructura y funcionamiento de las instituciones educativas en la configuración del espacio, tiempo y currículo y dice que se manejan con un pensamiento premoderno, mientras que los docentes, en su mayoría, han sido formados en la racionalidad moderna, y los estudiantes manifiestan conceptos, intereses, expectativas y comportamientos clara- 
mente postmodernos. Esta situación generaría una incoherencia en el ámbito educativo, en la cual sería compleja la comunicación, ya que se parte de diversos códigos y contextos sociohistóricos.

Estas ideas sirven de disparador para preguntarnos desde dónde y desde qué lógica pensar la construcción de los sujetos en el ámbito educativo. Una respuesta fundamental es un cambio epistémico que nos permita comprender la concepción del sujeto no como esencia o como algo dado, sino como acontecer, a partir de la capacidad autoreflexiva. La educación es así en un espacio público donde los sujetos se construyen en múltiples direcciones y alternativas, comprenden, indagan, proponen, se dinamizan en su desarrollo individual, al tiempo que dinamizan el entorno sociocultural.

Pérez Gómez en "La construcción del sujeto en la era global" 36 indica que el reto de la educación está en que los estudiantes (y los educadores, vale agregar) puedan transformar las teorías personales que construyen en su vida cotidiana para entender la realidad y actuar en ella, para ello tendrán que convertir la información en conocimiento y este en sabiduría. Este reto pedagógico que favorece la construcción del sujeto reside en la capacidad de crear y organizar escenarios de comunicación donde las relaciones humanas y los productos culturales que se intercambian en dicho contexto, estimulen y provoquen, por su calidad epistemológica y moral, la reconstrucción adaptativa y creativa de las teorías personales.

Solamente podemos estar satisfechos en la práctica docente cuando se produce un aprendizaje relevante, es decir, cuando los procesos de enseñanza/aprendizaje provoquen la ampliación y reconstrucción de las teorías personales con las que cada individuo interpreta el mundo y decide su conducta (Claxton,1987). En este sentido, 
"los contenidos disciplinares serán los mejores instrumentos que podamos ofrecer a los estudiantes para entender y actuar, preguntar y responder a dicha realidad problemática que afecta e interesa a los sujetos". "El valor educativo de los contenidos se aprecia cuando los saberes surgen como respuestas aún provisionales, parciales y tentativas a preguntas relevantes, a problemas sentidos". (Pérez Gómez, 2003).

Puesto que el conocimiento se construye siempre en la red de interacciones sociales, y que cada individuo se resiste a modificar sus teorías personales, la creación de un escenario de intercambios culturales de alto nivel, en contextos plurales e inteculturales, requiere la conquista previa de un clima de confianza, de tolerancia, de cooperación, de un creativo intercambio democrático a otras interpretaciones y la apertura a nuevos y más consistentes equilibrios también provisionales en nuestras concepciones, teorías y proyectos. Un ambiente de interacciones humanas respetuosas y de cuidado afectivo que permita al sujeto abrirse y poner al desnudo su esqueleto de representaciones frecuentemente erróneas y afrontar los conflictos cognitivos que requiere su desarrollo intelectual y social. Esto provoca la reconstrucción, ampliación y perfeccionamiento de las teorías personales y de los comportamientos autónomos y ha de implicar necesariamente, la participación voluntaria del aprendiz.

Promover la metacognición resulta una estrategia pedagógica imperiosa para la reconstrucción razonable de las teorías personales que son siempre subjetivas, provisionales, y parciales, saturadas de errores y prejuicios y la búsqueda de la relativa autonomía. Para este propósito es necesario que las instituciones educativas sean comunidades de aprendizaje donde los maestros y adultos de la comunidad aparezcan como modelos de aprendices ejemplares y como habilidosos facilitadores del arte de 
aprender. Esto implica saber aprender y tener la disposición de aprender lo que sea necesario, en cualquier escenario y a cualquier edad. Retomando conceptos anteriores vemos que a través de la educabilidad y educatividad los sujetos poseemos el potencial para construirnos mutuamente (o lamentablemente, para destruimos mutuamente también).

La filosofía dialogal o la filosofía de la intersubjetividad ${ }^{37}$ pueden resultar interesantes como marco de pensamiento para descubrir, una vez más en el siglo XXI, al otro como sujeto en devenir. Esta filosofía surge como respuesta al existencialismo ateo (Sartre, Heidegger, etc.) y destaca la dimensión interhumana. Mientras que Sartre ve en el otro "un infierno", Marcel o Buber ${ }^{38}$ consideran que yo y el otro configuramos una relación (cf. Gastaldi, 2003). ${ }^{39}$

El personalismo dialogal, también llamado así, proclama la trascendencia del "tú" para la existencia humana, o sea superar el individualismo y descubrir al "otro" para abrirse a los demás. Existir es co-existir, "ser para el encuentro" y la comunión. Para Buber; yo soy mi relación. No un yo que entra en relación, sino un yo que sale de la relación, emerge de ella. La relación me define; soy de acuerdo a cómo me manejo (cf. Barylko, 1998).40

El encuentro con el otro requiere responsabilidad, un trato ético, justo, amoroso. Y la palabra es un instrumento de este encuentro, de comunicación de sí mismo y medio de personalización. En la era de la información y de las comunicaciones, constantemente nos quejamos y nos topamos con incomunicaciones. Comunicamos cosas, ideas, informamos y nos informamos, pero la mayoría de las veces no nos comunicamos de ser a ser. El aprendizaje del encuentro requiere de libertad y la libertad es lo que construye sujetos autónomos y éticos. 
"La obra de cada uno de nosotros -y eso es lo que puede y debe enseñarse a los niños desde temprano- es la propia existencia como libertad creadora en busca de la felicidad. El mundo de los valores y de sus jerarquías sirve para orientarnos hacia esa deseada felicidad. Primero, en la ruta de lo general y universal, del Yo-Ello, de las confrontaciones diarias por el éxito, por el progreso, por el ascenso, que son humanas en la medida que son éticas, responsables, atentas a la presencia del prójimo como persona. A partir de allí estaremos abiertos, porosos en cuerpo y alma, a la presencia del otro. A partir de allí se producirá el encuentro con el otro como Tú, y ya no como utensilio-Ello. Entonces, nos saldremos del circuito de la ganancia y la pérdida, e ingresaremos en el extraño campo de la dicha, del amor". (Barylko, 1998)41

Espino Barahona ${ }^{42}$ presenta la relación pedagógica enmarcada en la "pedagogía de las ciencias del espíritu”. Una teoría de la educación cuyo punto nodal es la relación pedagógica. Esto es, una teoría desarrollada "a partir de la relación personal que se estructura en el encuentro del educador y el educando". (Wulf, 1998)43

"Una teoría tal no puede no dar una importancia ética fundamental a los sujetos que fundan dicha relación. Maestros y alumnos aparecen imbricados en una relación (pedagógica) que debe entenderse como una red de vínculos morales de relaciones con cierta permanencia y ordenada a fines -donde el estudiante es visto como "un ser en devenir", al cual debe tutelársele su derecho al desarrollo y a la autodeterminación. Éste es el telos de la educación según la pedagogía de las ciencias del espíritu: el de un educador que no elude la "aceptación de una responsabilidad pedagógica para los jóvenes que permita salvaguardar sus intereses" (Wulf, 1998). ${ }^{44}$ 
El encuentro educativo, docente-educando, no es una relación de pares sino una relación que encierra autoridad. Por eso, el docente aparece como persona de autoridad en el sentido etimológico de la palabra: "el que nutre y hace crecer". Autoridad era, en los orígenes, el hombre de consejo, de respaldo moral, el asesor. Hoy existen prejuicios en el concepto de autoridad. Pero quienes detentan autoridad en la familia, en las escuelas, en las instituciones, en el gobierno, deben ejercerla con un efectivo respaldo moral y como servicio a las personas y a la comunidad. El ejercicio docente debe estar impregnado de vectores axiológicos y toda autoridad pedagógica debiera generar confianza como condición indispensable en toda relación educativa que pretenda construir sujetos.

Pueden servirnos aquí los planteos de Habermas ${ }^{45}$ uno de los sociólogos actuales más representativo, cuando enmarca la dinámica humana en constantes individuales, sociales e históricas de dominación, engaño y búsqueda de poder. Y plantea la ruptura de este modelo -que solamente puede llevar a la extinción- con una teoría sobre la racionalidad, es decir, la habilidad para pensar de forma lógica y analítica. Este pensador imagina un futuro en el que la razón y el conocimiento trabajen en pro de una sociedad mejor. En ese futuro, la comunicación humana no debería estar sujeta a la dominación del Estado y los ciudadanos racionales deberían poder actuar en la sociedad de forma libre en el ámbito político. Este posicionamiento teórico y moral, propone una dinámica comunicativa, de diálogos y acuerdos como formas de práctica social. Para Habermas el bien del otro resulta mi propio bien y el cuidado del entorno social y natural que permita mejores condiciones de vida, tendría como objetivo la búsqueda del bien común. 
La teoría de la acción comunicativa de Habermas, indica que la interacción se da entre sujetos capaces de lenguaje y acción. El concepto clave es la interpretación, o sea la negociación de definiciones susceptibles de consenso. Para este pensador los mundos objetivo, social y subjetivo son construidos por la intersubjetividad; los sujetos crean y usan la racionalidad, la cual no es una realidad objetiva que se nos impone de forma determinada sin dejarnos margen de acción. Los sujetos que actúan comunicativamente son capaces de criticarse mutuamente.

Si bien no son propuestas que surjan desde ámbitos pedagógicos, los espacios de actuación de los sujetos de la educación están obviamente insertos en el plano social y no escapan a esta dinámica, por lo cual pueden aportar o no al desarrollo de esta racionalidad comunicativa.

Estas reflexiones deben servirnos para replantear nuestra acción en el aula, en las instituciones pedagógicas, o cualquier otro ámbito educativo ya que lo deseable en innovación educativa no consiste en que perfeccionemos tácticas para hacer progresos nuestra causa, sino en que mejoremos nuestra capacidad de someter a crítica nuestra práctica a la luz de nuestras creencias y nuestras creencias a la luz de nuestras práctica (cf. Stenhouse) ${ }^{46}$

Umpierrez ${ }^{47}$ al preguntarse por el nuevo sujeto pedagógico para la actual sociedad global, cita a Torres para afirmar que "la construcción del sujeto pedagógico es un problema conceptual central, un dilema de la democracia (...) el proceso de construcción del sujeto pedagógico democrático es un proceso de crianza (educación) cultural, pero también incluye principios manipulativos de socialización pedagógica y democrática en sujetos que no son tábula rasa en términos cognitivos o éticos, ni están totalmente provistos para el ejercicio de sus derechos y obligaciones democráticos". (Torres, C. 1996)48 
"Necesitamos asegurarnos que el camino seguido dignificará la vida humana, reconocerá los aspectos lúdicos y creativos de la gente y verá a los demás no como objetos de manipulación ni de liberación siguiendo los dictados de la mano invisible del mercado, sino como sujetos corresponsables comprometidos en el proceso de deliberación democrática sobre los medios y los fines de todas sus instituciones. (Apple, 1996) ${ }^{49}$

Compartimos ahora algunos cuestionamientos -que a la luz de lo ya tratado y como introducción a los próximos puntos- que pueden servir para reflexionar y evaluar nuestra labor y acción. ¿Somos amenazas para los demás? ¿Cómo docente soy una amenaza ante el educando o el educando se presenta una amenaza para el educador? ${ }_{i}$ El otro ayuda a construirme y encontrarme o me limita? ¿Interpela nuestra palabra, nuestro amor, nuestra obra? ¿Generamos aceptación o rechazo? ¿Qué violencias se producen en las instituciones educativas?

¿Cuántos docentes ayudamos al estudiante a "construirse", a encontrarse, a confiar en sí mismo y en sus potencialidades? ¿Cuántas actitudes docentes denigran y destruyen la subjetividad? ¿Cuántos prejuicios y burlas son depositadas en la vida de los estudiantes? ¿Cuántos conocimientos son realmente constructores de los sujetos y cuántos sólo ocupan un lugar sin modificarnos? Y viceversa....cómo estudiantes. ¿Cómo hemos contribuido a motivar a nuestros docentes? ¿Cómo los hemos respetado o cuánta indiferencia les hemos brindado?

Podríamos seguir preguntándonos y abordando múltiples ejemplos. Evidentemente, nuestra historia de sujetos está enraizada en muchas relaciones, está construida en muchos contextos e imaginarios de lo que somos y de lo que podemos llegar a ser. No por eso es menor la importancia de las relaciones entre educandos y educadores, 
las que configuran marcas y huellas que nos constituyen en nuestro pasado, presente y futuro.

Tal vez sea bueno apuntar al núcleo de la cuestión: ¿qué sujetos estamos formando y construyendo? ¿O qué acciones deberemos abordar para re-construir sujetos que llegan hoy a las instituciones educativas (sociales, políticas, culturales...) desfragmentados y aplastados? ¿Cómo comenzar a construir desde el inicio o a reconstruir desde los escombros?

¿Y qué hacer con educadores que no son tales y siguen "amaestrando" personas y modelando sujetos "sujetados"? ¿Qué condicionantes y qué opciones educativas existen que favorecen a unos más que a otros? ¿Qué espacios permitimos y creamos para que los otros puedan aprender diferentes lenguajes, desarrollar identidades y moverse en las fronteras de las diferencias culturales, para que puedan expandir las condiciones de su propia comprensión de las diferencias, como fundamento de una vida pública democrática? En suma, ¿qué sujetos se reproducen o se construye en la acción educativa?

Estos puntos nos ayudarán a autojuzgar la tarea educativa y redescubrir que acciones no debieran faltar. La primera tarea de todo educador será promover la capacidad fundamental del ser humano: la conciencia. Dejar en la inconciencia cuando se necesita y se puede provechosamente asumir una realidad para modificarla, es traicionar a las personas, los grupos y la sociedad. La toma de conciencia, la capacidad de interrogarse y de interrogar es el primer paso para un proceso de liberación y de madurez personal y comunitaria.

Otra tarea indispensable es conducir al sujeto a la libertad. Educar para que el otro sea y se sienta sujeto actor y no intérprete de otros papeles que él no eligió, ni quiere asumir. 
Los valores no pueden quedar ajenos a la tarea del educador. Más allá de toda moda y de insertar en el currículo de manera transversal (o de cualquier otra manera) la educación en valores, no puede faltar que el educando perciba los valores como respuesta a sus aspiraciones profundas, a sus ansias de vida, de verdad, de bien y de belleza, como camino para su inquietud de llegar a ser. Toda la educación es por lo tanto axiológica, culmina en la posesión vital y realización de valores, que se incorporan al obrar del sujeto educando, como hábitos buenos o virtudes.

Existen múltiples estudios y reflexiones que tratan la relación entre el sujeto educador y el sujeto educando, pero vamos a considerar aquí dos propuestas que a nuestro entender ayudarían al proceso de construcción de los sujetos pedagógico: la prevención y el encuentro.

\section{Prevención: una opción para la relación educativa}

En este apartado deseamos destacar el Sistema Educativo de Don Bosco como modelo de relación educativa.

El concepto base del Sistema Educativo de Don Bosco radica en lo preventivo, entendido como el "arte de educar en positivo" y "hacer que los jóvenes crezcan desde dentro, desde su libertad interior. Prevenir es sembrar gérmenes de vida, estar en la cotidianidad creciendo en y junto a los educandos por el camino correcto.

Otra instancia del sistema preventivo de Don Bosco es la de fundamentar su trabajo en los jóvenes a través de la transmisión del bien y de las experiencias positivas, sobre la belleza, la verdad, la bondad, la honestidad, y sobre experiencias pedagógicas positivas. Desde esta propuesta, un educador está convencido de que cualquier 
educando tiene en sí, energías de bien. El Sistema Preventivo se apoya en tres pilares insustituibles: la razón, la religión y el amor.

Lo preventivo como modelo pedagógico cree en los sujetos y los respeta como personas -valorizando el patrimonio natural y sobrenatural que cada uno lleva consigo-, proporciona un ambiente adecuado rico en valores humanos, se sustenta en sus aptitudes interiores, en su capacidad de pensar, en el amor, en su raciocinio, y lo prepara para el trabajo y la sociedad. El Sistema Preventivo es un modo de educación que evita el daño del educando y la necesidad del castigo; prescribe al educador una continuada convivencia con el estudiante y una completa entrega a su tarea educativa. No es sólo un método de pedagogía o disciplina, sino una síntesis de vida, de espiritualidad y pedagogía en dos vertientes: promoción humana y salvación cristiana: formar ciudadanos responsables y cristianos comprometidos. ${ }^{50}$

Don Bosco intuyó desde muy joven que para ganarse el corazón de los jóvenes era necesario acercarse a ellos, interesarse por sus cosas, "amar lo que ellos aman", para ello se esforzó en convertir sus colegios, casas las llamaba él, en una familia, donde se fomentan relaciones de familiaridad y confianza, donde hay también una autoridad que actúa desde la razón y el diálogo.

Desde un planteo actual, Peressón aborda el tema de la prevención en su artículo "Educar en Positivo" 51 y explora tres enfoques de la prevención en educación, que propone integrar y complementar: a) prevención como preparación y disposición para actuar anticipadamente; b) prevención como rehabilitación oportuna; c) prevención como arte de educar en positivo, que implica una sólida formación en valores y una "ecología del espíritu". La "educación en positivo" desde esta óptica mira la realización y la plenitud de la vida de cada persona. 


\section{Hacia la pedagogia del encuentro}

Alfonso López Quintás, catedrático de filosofía en la Universidad Complutense de Madrid, enseña que todo ámbito de encuentro, es un ámbito de formación y este concepto lo aplica a los ámbitos educativos. Cuando no hay ámbito de formación -dice Quintás- podrá haber cualquier otra cosa, por ejemplo, información, pero no formación. ${ }^{52}$

Cuando se vive un verdadero encuentro, siempre habrá una verdadera construcción y debe existir la acogida. Podemos relacionarnos, pero no encontrarnos y generar así intercambios instrumentales o mercantiles, contactos superficiales, choques virtuales, pero de ningún modo un encuentro.

El encuentro no es mera proximidad, sino que supone un ir y venir entre los seres que interactúan: una interpelación. Cuando uno habla y no hay respuesta, o cuando uno habla para acallar al otro, no hay encuentro. Sí lo hay, en cambio, cuando se crea una atmósfera en la que fluyen las preguntas y las respuestas. Como lo expresa Alfonso López Quintás:

"Toda relación de encuentro implica apelaciones y respuestas: me invitas a dar un paseo por un determinado lugar y yo accedo a ello, pero indico que sería preferible hacerlo en otro sitio. Mi respuesta es, por tanto, una apelación que te dirijo. El esquema que vértebra el encuentro no es 'lineal' (acción-pasión) sino 'reversible' (apelación-respuesta). Apelar significa invitar a asumir activamente un valor y realizarlo en la propia vida. De aquí se desprende que el encuentro no se da de un modo automático al anular las distancias y fundar una relación de vecindad. Exige un intercambio de posibilidades, y este no se da cuando los objetos se yuxtaponen, sino cuando dos o más ámbitos de realidad se 'entreveran', es decir, 
toman iniciativas conjuntamente y colaboran a una misma tarea. Esa forma de vinculación ha de ser creada libre y esforzadamente, porque plantea determinadas condiciones. Si dos o más personas no las cumplen, pueden convivir durante largo tiempo sin encontrarse ni una sola vez” (López Quintás, 1996). ${ }^{53}$

La pedagogía del encuentro se rige por la dimensión pragmática del lenguaje y se descubre que todo lenguaje es diálogo.

La conversación es una actividad de uno-conotro; es entenderse-con-alguien-sobre-algo; es un decir y dejarse-decir; es una actividad reversible de apelaciones y respuestas, que transforma a los interlocutores: En un encuentro conversacional, uno deja la esfera del yo para ingresar en la del nosotros e instaurar un intercambio entre el yo y el tú (Gadamer, 1992: 150) que discurre como un fluir de coordinaciones consensuales de acción, tal como sucede en el juego. En el encuentro creamos un campo de juego común, un campo de libertad común.

"La forma efectiva del diálogo se puede describir partiendo del juego... la fascinación del juego para la conciencia ludente reside justamente en ese salir fuera de sí, para entrar en un contexto de movimiento que desarrolla su propia dinámica. Mi idea es que la naturaleza del juego, consistente en estar impregnado de su espíritu espíritu de ligereza, de libertad, de la felicidad del logroy en impregnar al jugador, es estructuralmente afín a la naturaleza del diálogo, que es el lenguaje realizado. El modo de entrar en conversación y de dejarse llevar por ella no depende sustancialmente de la voluntad reservada o abierta del individuo, sino de la ley de la cosa misma que rige esa conversación, provoca el habla y la replica y en el fondo conjuga ambas. Por eso, cuando ha habido diálogo, nos sentimos llenos" (Gadamer, 1992).54 
Una pedagogía del encuentro tiene en cuenta a sujetos íntegros, con ricas experiencias capaces de instaurar un diálogo continuo con uno mismo, con los otros y con el mundo. EI sujeto se construye a sí en el intercambio, en la capacidad de entenderse y comunicarse con los otros para comprender el mundo y la convivencia con otros sujetos, para expresar las propias emociones-razones y someterlas a la crítica de los demás.

La importancia de la comunicación es destacada también por Prietto Castillo cuando nos dice que toda mediación pedagógica se funda en una propuesta comunicacional y que la comunicación es la base de la interacción entre seres humanos dispuestos a compartir la tarea de enseñar y de aprender. ${ }^{55}$

Los educadores somos seres de comunicación; los sistemas educativos son sistemas de comunicación; los materiales de aprendizaje son materiales de comunicación; los estudiantes son seres que crecen en la diferencia y en la comunicación. Una comunicación debe ser estimuladora para el otro, o sea que lo invite a salir de sí, a entregarse, a enriquecerse, a crecer.

Volviendo a Quintás, el autor incorpora el concepto de "experiencias reversibles" que son experiencias que tienen doble dirección, son importantísimas en la vida humana. En toda interacción bien entendida existen estas experiencias reversibles, intercambios; por ejemplo el educador influye en el educando y el educando en el educador.

Lo contrario de este tipo de práctica es una experiencia lineal: del sujeto al objeto. Quintás pone un ejemplo: "yo le doy un impulso al bolígrafo y el bolígrafo padece ese impulso y ahí se queda. El esquema que vertebra esta acción es el esquema acción/pasión: yo actúo-él padece. En la experiencia reversible no es así; yo actúo so- 
bre usted, usted actúa sobre mí, son dos acciones libres que nos complementan a los dos. Esto nos enriquece muchísimo”. (QUINTÁS, op. cit.)

Un rasgo de madurez en las personas es la posibilidad de actuar mediante experiencias reversibles y cada vez menos lineales. Por ejemplo, un institutor que espera sólo que sus estudiantes reciban lo que él les da, escuchen lo que él habla, sería un educador que vive de experiencias lineales. Pero si el profesor habla, actúa sobre los alumnos, pero ellos también reaccionan, por ejemplo, haciendo trabajos, planteando preguntas e iniciativas, es una experiencia reversible en la clase.

La pedagogía del encuentro halla en los valores, las capacidades para crear encuentro. Al llevar una vida virtuosa (valores que asumimos) creamos múltiples relaciones de auténticos encuentros, experimentando valiosos frutos: energía, alegría festiva, entusiasmo, felicidad, etc.

El autor expone algunas exigencias necesarias para llegar al encuentro: generosidad, veracidad y sinceridad, fidelidad, cordialidad, compartir valores elevados. Estas son virtudes que ayudan a encontrarse. No se podría acceder al encuentro desde vicios que encarnan antivalores (egoísmo, hosquedad, dureza, infidelidad, mentira).

Entonces, para que haya construcción de sujetos debe haber formación y para que haya formación debe ocurrir un encuentro entre sujetos, lo que aumenta la calidad de vida y la calidad de la formación.

\section{Conclusión}

Hablar de sujeto de la educación implica la necesidad de explicitar quien es el ser humano y cómo debe ac- 
tuar: ser y deber ser, como base fundamental de todo enfoque curricular. De ahí que el currículo conlleva una concepción antropológica y ética, una filosofía de la cultura, de lo social, de lo político, una opción axiológica.

Es necesario pensar en una educación desde la pedagogía del sujeto. Esto es trascender una educación transmisora que desarrolle individuos dependientes y alienados y optar por una educación para la creación de sujetos con autonomía social, con posibilidad de tomar decisiones, repensar la realidad, autocriticarse, proponer nuevos caminos y hacer y hacerse nuevas preguntas. Optar por una educación para el encuentro y la prevención. Una educación respetuosa de las culturas y de las diferencias, con reconocimiento de las características del educando, con orientación hacia la vida y las necesidades de este último, sustentada por valores de cooperación y solidaridad, con vocación de futuro y de construcción de sujetos y de sociedad.

Pero indicar aquí como lo resalta Burgos Rosa que con atender el discurso escolar no basta. El sujeto de educación se conforma en la práctica como un sujeto activo y condicionado tanto por las relaciones políticas, académicas, administrativas, jurídicas, etc., que rigen y se debaten en la institución escolar, como por discursos en otros espacios sociales, en la vida cotidiana, en espacios que son pedagógicos y educativos de manera informal o no formal y que contribuyen en la conformación del sujeto, delimitar sus condiciones, reconocer sus prácticas, qué fuerzas políticas actúan, qué contradicciones son emergentes, en fin qué tipo de sujeto constituyen y qué alternativas se pueden ofrecer.

Este tema nos excede aquí, pero puede obviamente abrir nuevas reflexiones a los lectores. 


\section{Notas:}

1 SAAVEDRA. A. "Las ciencias humanas y la filosofía de la Educación”. Sophia. Colección de Filosofía de la Educación. \# 1. Universidad Politécnica Salesiana- Abya Yala- Quito. Ecuador. Junio 2006 p 34. "¿Qué es educar, hoy? Utopía: Revista de formación y cultura $N^{\circ} 40$, año 9. 2005 pag. 2-5

2 JÓDAR F. \& GÓMEZ L.. "Una epistemología de la pluralidad, Sobre la alteridad y su exploración”. En La pedagogía y los imperativos de la época. Silvia Serra (coord.). Edición Novedades Educativas. Colección Ensayos y Experiencias. Bs. As - México. 2005 p. 22-31

3 LERENA C. Reprimir y liberar. Crítica sociológica de la educación y de la cultura contemporánea. Madrid. Akal, 1983 citado por Jódar y Gómez, p.9

4 GIROUX H. A. "Enseñanza, aprendizaje y ética: Reconstrucción de la vida democrática pública”. Entrevista realizada por Joaquín Ramos García

Disponible en http://www.quadernsdigitals.net/datos_web/ hemeroteca

5 A la capacidad de la psique de crear un flujo constante de representaciones, deseos y afectos, se le denomina imaginario radical (como fuente de creación) (Franco 2003). El imaginario no deberá entenderse como imagen de, sino como creación incesante e indeterminada, ubicada en las subjetividades particulares, por tanto reconociendo la existencia de un sujeto de la imaginación y del deseo (Baeza 2000). Juan Luis Pintos (2000) conceptualiza los imaginarios sociales como «aquellos esquemas construidos socialmente que nos permiten percibir, explicar e intervenir en lo que cada sistema social se considere como realidad» El imaginario radical es el imaginario individual o imaginación radical, pero el imaginario social no es la suma de imaginarios radicales, ni la parte común, ni "la media". Lo que el individuo es capaz de producir no son instituciones, son fantasmas privados (Castoriadis 2003:250). El ser humano del imaginario radical es un ser humano que dispone de unos significantes colectivamente disponibles, que le permite hacer de las imágenes símbolos. Estos significantes colectivos son para Rorty (1996) herramientas del lenguaje que nos constituyen y que se expresan a través de nuestra conciencia, nuestra cultura, nuestra forma de vida. 
HURTADO HERRERA D.R. Reflexiones sobre la Teoría de Imaginarios. Una posibilidad de comprensión desde lo instituido y la imaginación radical. Facultad de Ciencias Sociales. Universidad de Chile. Diciembre 2004. http://www.moebio.uchile.cl/21/hurtado.htm

MANGANIELLO E. Introducción a las Ciencias de la Educación. Librería del Colegio. Bs. As. Vigésima Edición. 1988.

GASTALDI, ITALO. El hombre un misterio, Abya Yala, Sexta Edición. Quito, Ecuador. 2003.

9 ORTEGA Y GASSET. Meditación del Quijote. Madrid. 1975, p. 30... "el hombre es él y sus circunstancias".

10 COLL. C. "Psicología y Currículo”. Editorial Laia. Barcelona. 1987 citado por HUBERMAN S. ¿Cómo aprenden los que enseñan?. La formación de los formadores. Ediciones Aique Didáctica. Bs. As. 1996.

11 La palabra cultura significa fundamentalmente un estilo de vida, un modo habitual de valorar, de vivir conforme a una jerarquía de valores y, por consiguiente, un modo de ser. Ese modo de ser y valorar se transmite de generación en generación. Y en esa tarea de transmisión la educación juega un papel realmente preponderante.

12 HUERGO A. "Desbordes y conflictos entre la cultura escolar y la cultura mediática”. Disponible en http://www.udp.cl/ comunicacion/magcom/docs/cultura.doc.

13 La idea del diálogo (Bajtin, 1982) remite a que una configuración textual es básicamente interdiscursiva y, por consiguiente, un fragmento de la memoria colectiva. Es, en este sentido, una sedimentación posible de una determinada acumulación narrativa. En el diálogo la comunidad (histórica y geográficamente situada) habla y, en un mismo movimiento, es hablada. En el diálogo se expresa la cultura como campo de lucha por el significado, en la que se reflejan una multiplicidad de valores, voces e intenciones, con distintos grados de intensidad en sus contradicciones.

14 El interjuego entre interpelaciones y reconocimientos (o no reconocimientos) en la producción de una formación hegemónica y de la ideología, ha sido trabajado por Ernesto Laclau (Laclau y Mouffe, 1987) y por Slavoj Zizek (1992).

15 BUENFIL BURGOS, R. N. Análisis de discurso y educación. México, DIE 26, Instituto Politécnico Nacional. 1993.

16 ÁVILA PENAGOS, R. La cultura. Modos de comprensión e investigación. Bogotá: Antrophos Ediciones. 2001. p. 32 
17 MARTÍN- BARÓ. La coherencia en los compromisos. Introducción a Psicología de la liberación, Madrid: Trotta. 1998.

18 Entrevista con Hugo Zemelman y Estela Quintar. Pedagogía de la dignidad de estar siendo. Ver referencia 32.

19 LIBEDINSKY, M. La innovación en la enseñanza. Argentina, Paidós.2001.

20 ROGERS, C Libertad y creatividad en la educación en la década de los 80. Barcelona. Paidós. 1986.p. 46.

21 APPLE. M. El conocimiento oficial. Paidós. España. 1996.

22 FREIRE, P. La educación como práctica de la libertad. Siglo XXI editores, Argentina. 1969. p. 39

- Pedagogía del oprimido. Siglo XXI editores 53a. Edición. México. 2000

23 UMPIERREZ A. "Globalización, curriculum y profesorado o la forma en que el poder de la diferencia actúa en educación”. Revista Contexto educativo. $N$ 29, año 5. Disponible en http://contexto-educativo.com.ar/

24 El concepto alude a un proceso externo y ritualizado en el cual el maestro deposita (o cree depositar) en el otro (educando) lo que él posee. Así, los estudiantes son vistos como "vasijas vacías, meros recipientes de las palabras del educador".

25 Dice Freire: “... a) el educador es siempre quien educa; el educando el que es educado, b) el educador es quien sabe; los educandos quienes no saben, c) el educador es quien piensa, el sujeto del proceso; los educandos son los objetos pensados, d) el educador es quien habla; los educandos quienes escuchan dócilmente, e) el educador es quien disciplina; ..." (Freire, 1976:74)

26 HAMMOND, L. en Libedinsky, M La innovación en la enseñanza. Argentina. Paidós. 2001. p. 93.

27 SANTOS GUERRA. La formación docente inicial. Barcelona. Revista Cuadernos de Pedagogía, No 220. 1993.

28 BIRGIN, A \& DUSCHATSKY, S. "Problemas y perspectivas de la formación docente". En Los condicionantes de la calidad educativa. Filmus, D (comp.) Argentina. Ediciones Novedades Educativas. 1995

29 CASTRO, S. La formación docente en América Latina. UNESCO/OREALC, Santiago de Chile. 1991.

30 DAVINI, C. La formación docente en cuestión: política y pedagogía. Bs. As. Paidós. 1995.

31 LISTON Y ZEICHNER. Formación del profesorado y condiciones sociales de la escolarización. Madrid. Morata.1993. 
32 La tradición reconstruccionista social, de reforma de la formación del profesorado en los EEUU, define la escolarización y la formación del profesorado como elementos cruciales del movimiento a favor de una sociedad más justa. Liston nos presenta diversas tradiciones de formación en Estados Unidos durante el siglo XX: tradición académica, la tradición de la eficacia social, la desarrollista y la de reconstrucción social.

33 GIROUX, H “Teoría de la Formación el Profesorado". Revista Educación No 284. Hispagraphis, Madrid. 1987. p. 53-76.

34 Hugo Zemelman es epistemólogo y cientista político mexicano. Resulta interesante el diálogo entre Zemelman y Estela Quintar, como un espacio entretejido entre dos intelectuales latinoamericanos. La entrevista realizada por Jorge Rivas Diaz tiene por titulo "Pedagogía de la dignidad de estar siendo", fue realizada en marzo del 2005 en la sede de IPECAL (Instituto de Pensamiento y Cultura en América Latina). Puede consultarse en Revista Interamericana de Educación de Adultos (RIEDA), edición de junio 2005 en el sitio http://tariacuri.crefal.edu.mx/crefal/rieda/ ene jun 2005

35 HARGREAVES, A. Profesorado, culturalidad y modernidad: cambian los tiempos, cambia el profesorado. Madrid. Morata. 1996.

36 PÉREZ GÓMEZ, Á.. "La construcción del sujeto en la era global". Sestao. Noviembre 2003. Disponible en www.telefonica.net l.../Ponencia

37 Son pioneros de esta corriente, aparecida en Europa al fin de las Primera Guerra Mundial, Buber, Levinas, Marcel, Mounier, Ebner, Guardini etc. El personalismo dialogal toma la realidad de la "persona en comunión" como base universal y radical de la reflexión filosófica.

38 BUBER, M. Yo $y$ tu, Bs. As. Nueva Visión, 1979.

39 GASTALDI, I. El hombre un misterio, Abya Yala, Sexta Edición. Quito, Ecuador. 2003.

40 BARYLKO J. La filosofía, una invitación a pensar. Ediciones Planeta. Argentina. 1998.

41 Idem. p. 252-253

42 ESPINO BARAHONA E. A. "Semiótica y relación pedagógica. Hacia la cualificación ética de la práctica docente. Revista Iberoamericana de Educación. Disponible en www.rieoei.org/deloslectores/621Espino

43 WOLF, CRISTOPH. Introducción a la ciencia de la Educación. Asonen. Medellín. 1998. p. 55 
44 Idem \#43.

45 La obra de Habermas constituye un ataque radical a la idea de que el positivismo, la ciencia y la investigación moderna son objetivas. Opina que la ciencia y la tecnología están más bien regidas por valores e intereses que a veces contradicen la búsqueda desinteresada de la verdad. Habermas sostiene que la sociedad tecnológica y el consiguiente aumento de la burocracia han servido, entre otras cosas, para perpetuar las instituciones del Estado y despolitizar a los ciudadanos. De esta forma la razón y la ciencia se han convertido en herramientas de dominación más que de emancipación.

Puede consultarse al respecto: Fecha Ramón, Gómez Jesús, Puigvert Lidia. Teoría sociológica contemporánea. Paidós. España. 2001.

46 STENHOUSE, L. Investigación y desarrollo del currículo. Editorial Morata, Madrid, 1984.

47 Ver nota \# 23

48 TORRES, C. A Las secretas aventuras del orden. Estado y educación. Miño y Dávila Editores. Bs. As, Argentina. 1996-. p. 56

49 APPLE, M. Política cultural y educación. Morata. Madrid, España. 1996. p. 15

50 Cf. PERAZA. FERNANDO El Sistema Preventivo de Don Bosco. Centro Salesiano Regional. Tercera Edición. Quito. Ecuador. 2001 y GARCÍA JORGE, Conociendo a Don Bosco. Centro Salesiano Regional. Quito. Ecuador. 2001

51 PERESSON M. Educar en Positivo. Publicado en Sophia, Colección de Filosofía de la Educación. \# 1. Universidad Politécnica Salesiana- Abya Yala- Quito. Ecuador. Junio 2006. pag. 235-271

52 LÓPEZ QUINTÁS, A. ¿Cómo lograr una formación integral?. Madrid: San Pablo. 1996

53 LÓPEZ QUINTÁS A. "La Formación Adecuada a la Configuración de un Nuevo Humanismo". Conferencia, en dos partes, en la asignatura Filosofía de la Educación II de la Faculdade de Educação da Universidade de São Paulo, el 26 -11- 99, para los alumnos del segundo año de Ciencias de la Educación y para numerosos profesores y doctorandos de la FEUSP y de otras universidades de São Paulo- Edición: L. Jean Lauand. Disponible en http://www.hottopos.com.br/mirand9/quintas.htm http://es.catholic.net/educadorescatolicos/693/2399/ articulo.php?id=21849 
54 GADAMER, HANS-GEORG. Verdad y Método. Tomo II. Ediciones Sígueme. Salamanca. 1992. p. 150-151

55 PRIETO CASTILLO, D. Educar con sentido. Apuntes sobre el aprendizaje. Universidad de Cuyo. Argentina. 1993. 